\title{
EL MUNDO FELIZ \\ DE SARAH KAY \\ O CUANDO LA CULTURA \\ IMPRESA ENTRETIENE \\ Y EDUCA A LAS NIÑAS, \\ ARGENTINA A PARTIR \\ DE 1979
}

PAULA CALDO

${ }^{1}$ Unidad Ejecutora en Red Investigaciones Socio-históricas Regionales del Consejo Nacional de Investigaciones Científicas y Tecnicas - Universidad Nacional de Rosario. Correo electrónico: paulacaldo@ gmail.com

\section{Resumen}

El presente artículo tiene por objeto analizar las ilustraciones de Sarah Kay. Una serie de dibujos que Vivien Kubbos elaboró a fines de la década de 1970 y que la Editorial Atlántida introdujo en el mercado argentino con el propósito de ornamentar objetos de uso exclusivo de niñas. Específicamente, las ilustraciones serán un pretexto para traer a la reflexión la problemática de la construcción de la feminidad y hacer jugar así uno de sus correlatos: la teoría de género. A los efectos de enriquecer el planteo, triangularemos aportes de la historia de las mujeres, la historia sociocultural y la pedagogía.

Palabras clave: mujeres, infancia, imágenes, educación, identidad, análisis visual. 


\begin{abstract}
This article intends to analyze Sarah Kay's illustrations. A series of drawings designed by Vivien Kubbos in the late seventies, which were introduced in the Argentine market by Editorial Atlántida with the purpose of embellish objects created for the exclusive use of girls. Specifically, this illustrations will be a pretext to bring to reflection the problem of construction of femininity and so putting into play one of its derivatives: the genre theory. In order to enrich this proposal, we will triangulate contributions from Women's History, Social Cultural History and Pedagogy,
\end{abstract}

Keywords: women, childhood, illustrations, education, identity, visual Analysis.

\title{
INTRODUCCIÓN
}

En el presente artículo escogimos como eje de reflexión las ilustraciones conocidas bajo el signo: Sarah Kay. En la década de 1970, esos dibujos fueron elaborados por la artista plástica Vivien Kubbos, y llegaron a la Argentina gracias a la gestión comercial de Editorial Atlántida, cuando corría el año 1979. Atlántida las utilizó como ornato de objetos de uso exclusivos de niñas, reunidos en una colección llamada: Mundo feliz. No obstante, lejos de biografiar a Kubbos o 
analizar el potencial artístico de las imágenes creadas, en estas páginas las ilustraciones serán un pretexto para reflexionar en torno a las estrategias educativas programadas desde la cultura impresa para formar, en este caso, a las niñas. En otras palabras, nos interesa reflexionar alrededor de cómo y con qué fuerza performativa aparecieron estos dibujos claramente femeninos adornando los productos de Atlántida. Justamente, a los efectos de enriquecer el planteo triangularemos aportes de la historia de/con mujeres junto a algunos conceptos de la filósofa Judith Butler, de la historia sociocultural y de la pedagogía. Mientras que la primera permitirá poner en escena la problemática femenina en la Argentina de los años setenta, la historia sociocultural facilitará interpretar las imágenes, el mundo editorial, la cultura impresa y las prácticas de consumo; y la pedagogía, en consonancia con la historia de la educación, introducirá el problema de la educación y sus proyecciones sobre las identidades de los géneros. A la vez, es importante recuperar la profusión de estudios que, en el presente, están tomando la relación entre palabra e imagen a los efectos de analizar prácticas pedagógicas situadas en escenarios que exceden a las escuelas. En esta dirección, el análisis de los productos editoriales se vuelve crucial y constituye un disparador de nuestra interpretación (Malosetti Costa, Gené, 2013). Por tanto, en una clara apuesta interdisciplinaria, interrogamos al mundo feliz de Sarah Kay con el propósito de reflexionar alrededor de las líneas de feminidad transmitidas. 


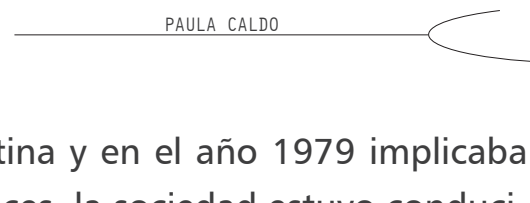
algunas cuestiones. ${ }^{2}$ Por entonces, la sociedad estuvo conducida por un gobierno dictatorial, el más cruento que conoció la historia del país, cuya forma de ejercer el poder fue el Terrorismo de Estado (Suriano, 2005). El llamado Proceso de Reorganización Nacional (1976-1983), al tiem-

${ }^{2}$ El periodo 1976-1983 está indicado como uno de los tiempos más críticos, violentos y traumáticos de la historia de la Argentina. En los últimos años emergió una profusión de estudios sobre el mismo que dificulta hacer síntesis. Sin embargo y a modo de referencia bibliográfica, citamos: Juan Suriano (2005). En materia de educación pueden consultarse: Carolina Kaufmann (2001) y Delfina Doval y Carina Rattero (2011).

po que implementó una gestión política y económica de corte neoliberal, con duros ajustes para una población por entonces politizada; persiguió y clausuró una multiplicidad de manifestaciones culturales. En otros términos, la censura, el miedo, las desapariciones, la clandestinidad y la ausencia de justicia legitima, oprimieron a la sociedad. Empero, como contrapartida, fue permitida una serie de acontecimientos masivos que, siendo altamente pasionales, creaban la ilusión de vivir en una sociedad ordenada, patriótica y entusiasta, cual Mundo feliz. La victoria en el mundial de fútbol de 1978, las manifestaciones de euforia y devoción nacional en los tiempos de la Guerra de Malvinas (1982) o la frágil e ingenua alegría provocada por la música, el cine, la literatura y el teatro no amonestado por la censura de la época.

En este marco, la infancia no quedó fuera de la vigilancia y el control. Esta franja etaria fue objeto de intervenciones varias. Primero, como escolares estuvieron supervisados por el ojo atento y sigiloso de los/as agentes del Estado. Una intrusión 
dada en el plano de los contenidos curriculares y de las prácticas cotidianas (rituales, actos, música, uniformes, etc.). En segundo lugar, los/as infantes/as comenzaron a ser contemplados por el mercado no solo a partir de la circulación de juguetes importados sino también de productos editoriales, cinematográficos y de televisión. Como contrapartida, se aplicó estricta censura sobre una gran variedad de relatos e historias infantiles. ${ }^{3}$ Finalmente, las niñas y niños fueron igualmente objeto de

${ }^{3}$ Algunos de los títulos censurados fueron: Un elefante ocupa mucho espacio, de Elsa Bornemann; La torre de cubos de Laura Devetach; La ultrabomba y El pueblo que no quería ser gris (editados por Augusto Bianco), entre otros. representaciones gráficas. Las caricaturas de estos/as aparecieron con diferentes formatos y tonalidades. Así, se cruzaron los personajes de García Ferré (con sus animales parlantes, adultos/as infantilizados/as, niños/as valientes, entre otros) con el niño gaucho (logo del Mundial '78) y, entre otros tantos, fue incluida también la siempre crítica Mafalda de Quino que, casi como un gesto de su inteligencia, logró resistir en tiempos de extrema censura (Cosse, 2014). En medio de aquel panorama, Editorial Atlántida incorporó, entre sus múltiples propuestas, las representaciones de la artista australiana conocida bajo el pseudónimo: Sarah Kay.

Como dijimos, en estas páginas realizaremos un ejercicio reflexivo sobre esas imágenes, acentuando en el análisis el modo en que fueron incorporadas en las publicaciones y productos de papelería difundidos por Atlántida. Las miraremos con ojo agudo, discutiremos sus formas y colores, y también las pondremos en el contexto de sus vehículos de difusión: libros, revistas, etc. 


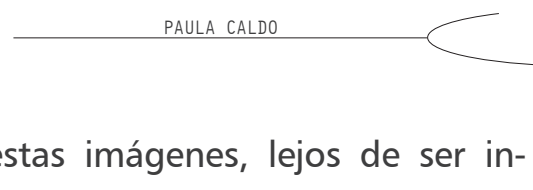

Tal ejercicio presupone que estas imágenes, lejos de ser ingenuas, contenían una carga pedagógica, buscaban impactar en la identidad femenina $y$, de ese modo, direccionaron un modo de ser y de aparecer femenino. Sarah Kay fue un recurso de la cultura pedagógica que, en los años negros de la Argentina, pintó para las niñas un mundo feliz. En otras palabras, ensayaremos la descripción densa de una serie de productos consumidos por las niñas argentinas mientras vivían en dictadura. ${ }^{4}$

${ }^{4}$ Aclaramos que este trabajo sólo analiza los obje-
tos ornamentados con los dibujos Sarah Kay, no así
la recepción de los mismos. Esto último es una tarea
pendiente y necesaria que vendrá a completar la pri-
mera lectura interpretativa de estas ilustraciones.
Esta investigación responde a un proyecto mayor que
apunta a estudiar los recursos de la cultura destinados
a educar a las mujeres en Argentina. El mismo está
radicado en el Consejo de Investigaciones Científicas
y Tecnológicas (Argentina).

\section{EL MUNDO FELIZ DE SARAH KAY Y SUS VECTORES DE VISIBILIDAD: COLORES, FORMAS Y PRÁCTICAS}

Sarah Kay: una historia sencilla y verdadera.

La historia comienza en Australia. En un barrio de Sídney había una señora que hacía unos dibujos muy especiales. Su nombre: Sarah Kay. Un día alguien descubrió su talento. Y sus ilustraciones se utilizaron para tarjetas de fin de año. El éxito fue total. Primero en Australia, después en el mundo entero. Ahora las creaciones de Sarah Kay llegan a la Argentina. Y ya no son solamente tarjetas. Hay también diseños para postales, almanaques, cuadernos, libros, álbumes, agendas. Son algo distinto, tierno, cotidiano, íntimo... Con 
el encanto de las cosas sencillas que nunca pasan de moda.

Vamos, acércate ahora mismo al mundo feliz de Sarah Kay. Una exclusividad de Editorial Atlántida en todas las librerías.

1979 AÑO INTERNACIONAL DEL NIÑO (Para ti, 1979, abril 15).

Como ya dijimos, en el año 1979 comenzaron a circular en Argentina las ilustraciones de Vivien Kubbos, conocida bajo el pseudónimo: Sarah Kay. Editorial

${ }^{5}$ Editorial Atlántida fue fundada en el año 1918 (perdurando hasta la actualidad) por el uruguayo Constancio C. Vigil. Se encargó de publicar una serie de productos que se inscribieron en el proceso de apertura del público lector. Para ampliar referencias sobre la citada editorial ver: Paula Bontempo (2012).
Atlántida ${ }^{5}$ fue la encargada de llevar adelante tal tarea por dos vías: los productos de papelería (cuadernos, figuritas adhesivas, libretas, diarios, libros de recuerdos escolares, papeles de cartas, invitaciones de cumpleaños, álbumes, etc.) y la promoción de los mismos en revistas producidas por la editorial, estuviesen estas dirigidas al público femenino como Para ti (1922) o directamente al infantil como Billiken (1919), o la misma Gente (1965) que estaba orientada a los adultos en general (Eujanian, 1999; Ulanovsky, 2005; de Diego, 2006).

Desde el año 1919, Billiken estuvo destinada a los/as niños/ as en edad escolar (Guitelman, 2006). La revista se abocó a complementar el desarrollo escolar con notas, informes y 


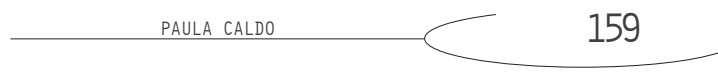

actividades, y también traía consigo una propuesta lúdica para entretener en los momentos de ocio. Por otra parte, la publicidad estuvo presente en sus páginas, privilegiando aquellos productos elaborados por la misma editorial (Sosenski, 2012). En esta dirección, en el año 1979 inició la promoción de los artículos de la serie Sarah Kay con las siguientes consignas: "Sarah Kay. MUNDO FELIz. Amistad - ternura - felicidad. 1979 - AÑO INTERNACIONAL DEL NIÑO". ${ }^{6}$ EI

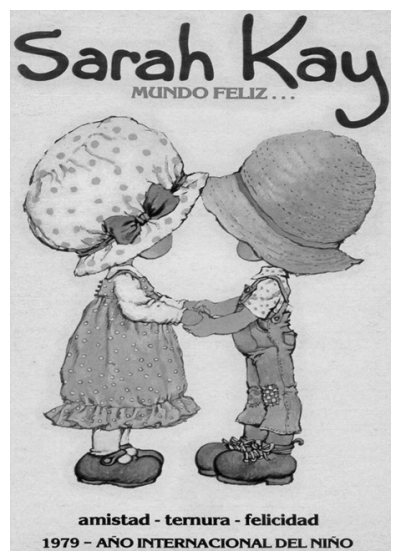
texto citado acompaña las siluetas de un niño y de una niña, ambos de perfil y tomados de la mano. ${ }^{6}$ La publicidad que contiene esta frase apareció
en diferentes números de la revista Billiken du-
rante los años 1979 y 1980 .

La pareja compone la imagen prototípica de los granjeros australianos. Al varón se lo percibe enfundado en un pantalón enterizo de color tierra que solo deja asomar las mangas de una camisa blanca. Su cabeza está cubierta con un sombrero de paja y en los pies lleva zapatos acordonados. La niña luce un vestido con lunares cuya base cierra en un volado en los mismos tonos que el atuendo del muchachito. Asimismo, el vestido es combinado con una camisa, de la cual solo pueden verse las mangas y el cuello, de color blanco. El vestuario se completa con unos zapatos prendidos en pulsera y un sombrero de tela blanco con lunares y adornado con un moño. Estos infantes conformaron una de las imágenes representativas del Mundo feliz 


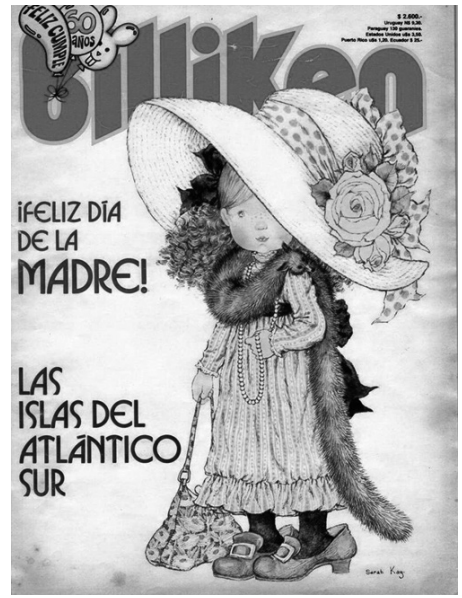

de Sarah Kay. Nada podemos decir acerca del lugar donde se encuentran los pequeños amigos porque el fondo de la imagen es de un homogéneo marrón claro. Inferimos que, al encontrarse fuera de cualquier contexto particular, estos/as niños/as representan una concepción universal de la infancia, entendida en términos de sencillez, pureza y ternura. La misma imagen fue impresa en portadas de cuadernos y de carpetas, en separadores de materiales, marcadores de libros, etiquetas, diarios íntimos, libretitas, papeles de cartas y en los sobres que contenían las figuritas coleccionables del álbum correspondiente.

Estos dibujos, además de aparecer en las publicidades de Billiken, figuraron también en el contenido de la revista. Oportunamente, en el mismo año 1979, una de las ilustraciones de Sarah Kay fue utilizada como portada del número alusivo al Día de la madre (Billiken, 1979, octubre 16). La imagen en cuestión solo aparece en la portada, no así en el interior de la revista donde no se hace mención a la presencia de tal figura introductoria. En esta ocasión se presenta a una niña de tez blanca y cabellos castaños ondulados, vestida con prendas y accesorios que, a todas luces, revelan ser de una mujer adulta, presuntamente la madre. Lleva un vestido en tonos pasteles con sutiles líneas de flores y lunares. La 


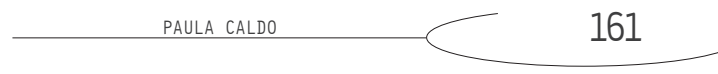

prenda central está engalanada con: una estola de piel que rodea el cuello, un collar de perlas, zapatos de tacón, un bolso y una capelina. La pequeña jugando a ser grande o, lo que se considera análogo, a ser mamá, se convierte en un homenaje pero también es un ensayo preliminar de lo que se estimaba como futuro de toda niña: la maternidad. ${ }^{7}$ Nuevamente la imagen tiene un fondo neutral que no deja de ser simbólico: el color blanco estimado muchas veces como símbolo de pureza pero que, de todos modos, impide situar a la muchacha en un lugar singular.

A los personajes de Sarah Kay se los podía encontrar en las páginas de Billiken y en las de otras publicaciones de la misma editorial ${ }^{8}$. Por ejemplo, el semanario femenino Para ti, además de reproducirlos en anuncios publici${ }^{7}$ Una profusión de textos analizan el vínculo muje-
res-maternidad. En este caso mencionamos el trabajo
de Marcela Nari (2005) porque en él se estudia el pro-
ceso político de construcción de la maternidad como
una práctica para nada natural y siempre direcciona-
da y tutelada por el Estado y por las políticas de cada
época.
${ }^{8}$ En su análisis de la revista Billiken, Paula Guitelman
(2006) destaca la auto-cita de Atlántida, en tanto
todas las citas, referencias bibliográficas o productos
promocionados eran elaborados bajo el propio sello
editorial. Por ejemplo, Billiken ofertaba libros, produc-
tos de papelería y demás materiales de Editorial Atlán-
tida. Lo que da por resultado la presencia del mundo
cerrado de Atlántida. tarios, lo hizo en el marco de sus notas. En las secciones de moda se mostraron remeras con estas estampas y en otras se exponían sugerencias para regalar. Bajo el título "Para tentar a cualquiera", se explicó:

Salió una nueva línea de cuadernos y anotadores con diseños de la dibujante australiana Sarah Kay, cuya producción está a cargo exclusivamente de la Librería 
Atlántida. Cuadernos grandes con espiral (\$ 4.200), block grande (\$5.000), block mediano (\$2.300); block chico (\$ 1.640); block alargado (\$2.500); cuadernos de 12 hojas ( $\$ 800)$; block con espiral a un costado ( $\$$ 5.800). Estos precios son aproximados. Se pueden adquirir en Virgilio Domínguez, Florida 343 y Librería Sarmiento, Libertad 1241 (Para ti, 1979, mayo 11).

La nota contribuía con los anuncios del lanzamiento de la colección de productos Sarah Kay, un mundo feliz. Desde sus orígenes en el año 1922, la lectora ideal de Para ti fue la mujer moderna. Una mujer bella, hacendosa, capaz de combinar el trabajo doméstico con los trabajos extramuros del hogar y de condimentar todo eso con un buen gusto por la moda, la decoración, la recreación familiar, etc. La intención era que el magacín circulara entre madres e hijas, para lo cual se mostró una sutil correspondencia entre notas y temas de mujeres maduras con otras dirigidas a las jóvenes (en vías de casamiento o recién casadas) y a las adolescentes (Bontempo, 2012). De hecho, al finalizar los años setenta la Editorial Atlántida se pronuncia en favor de aquellos discursos que promueven el ideal doméstico de mujer. Lo hará en un contexto donde el clima represivo vino a frenar, entre otras cosas, el estallido de la liberación femenina y de su emblema, la joven liberada. Esta última desafiaba los mandatos tradicionales, negándose al matrimonio y, en esa acometida, discutiendo el sentido de la maternidad como fin 


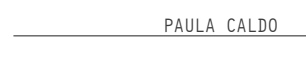

esencial de la realización femenina (Cosse, 2009). Contra este modo de habitar la feminidad se levantó la voz de Atlántida y lo hizo, entre otras estrategias, apelando a las ilustraciones de Sarah Kay.

Como ya dijimos, la serie de productos ornamentados con estos dibujos se llamó Un mundo feliz. Ese Mundo se expuso por medio de diferentes soportes gráficos, de los cuales, a los fines de nuestro análisis, hemos seleccionado dos, por ser justamente los que triangularon imágenes con epígrafes y, de esa manera, muestran el sentido atribuido por la editorial a cada uno de los dibujos. Estos son: los libros de pequeñas historias con ilustraciones y los álbumes de figuritas autoadhesivas para coleccionar. Es preciso abrir un paréntesis para aclarar que muchos de estos productos presentaban las caricaturas despojadas de epígrafes: portadas de carpetas, separadores de materias, canoplas, lápices de colores, cuadernos, anotadores, libretas, etc. Así, solo la semántica creada por la pluma de la ilustradora impactaba en las muchachitas consumidoras.

Ahora bien. La serie de libros Un mundo feliz comenzó a editarse en 1982 y en-

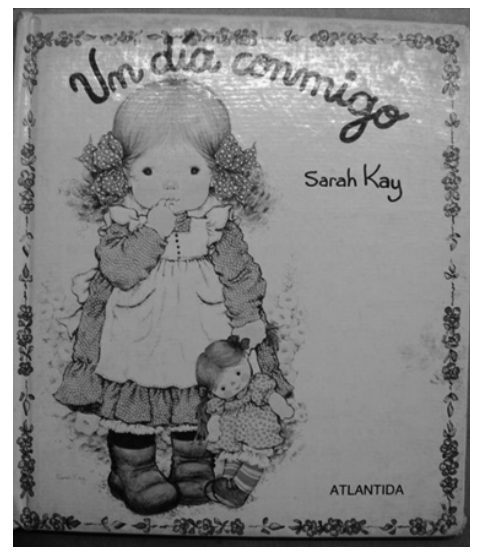
tre sus títulos se encontraban: En la granja, Vamos a jugar, Las vacaciones, Un día conmigo, iQué día!, Bellas historias, Mis juegos y juguetes, entre otros. Si bien en 
los libros no se detalla el número de ejemplares comprendidos en la tirada, sí es enunciado el número de edición. Es interesante advertir que algunos dicen ser la cuarta o quinta edición, dato que denota el acentuado consumo de los mismos. Pasando a la descripción del contenido de los textos, estos básicamente con una serie de ilustraciones acompañadas por frases breves. Son relatos fragmentarios, cuyo denominador común es el título del volumen. Por ejemplo, en el libro Vamos a jugar vemos a niñas y a niños ensayando una diversidad de juegos: la maestra, la casita, la mamá, la enfermera, el pescador, la veterinaria. Esos juegos transcurren en la habitación de la casa, el comedor, las márgenes del río, el patio de la granja, cerca de árboles, la cocina, etcétera (Kay, 1983a) Las oraciones que acompañan a las ilustraciones son del siguiente tenor:

\footnotetext{
${ }^{9}$ La imagen muestra a una niña junto a su muñeca (Kay, 1983a: 8).

${ }^{10}$ El texto oficia de epígrafe a una imagen de una niña que está jugando a la maestra con sus muñecos. Como maestra, la pequeña está de pie frente al pizarrón con la típica postura estimada correcta para las educacionistas. Esta es, el cuerpo se acomoda de manera tal que permita tanto escribir como contemplar al grupo clase. Por su parte, los/as alumnos/as (muñecas y animalitos de felpa) aparecen sentados en hileras, respetando estaturas y teniendo frente a sí dispuestos cuadernos y libros (Kay, 1983b: 6).

${ }^{11}$ El texto acompaña una imagen de una niña que está cultivando plantas junto a un gatito (Kay, 1983c: 10).
}

Qué difícil ser mamá y no perder la razón. ${ }^{9}$

iNo me hagan enojar: silencio toda la clase! Para aprender a sumar deben ser siempre constantes y mejor si tienen algo de memoria de elefante... ${ }^{10}$

Cuidado, ternura, amor necesitan las plantas para dar flor, son como las personas, como tú y como yo. ${ }^{11}$ 


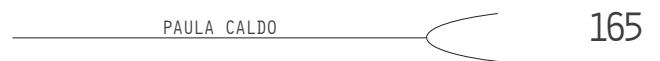

La colección está dirigida a los niños en general; no obstante, el contenido de los relatos recrea expresiones o sentimientos propios de los personajes femeninos. Prueba de ello son: los susurros de las muchachas románticas que sueñan con el vuelo de las mariposas; la pequeña que sufre y expresa los avatares de la maternidad (con su muñeca en mano) o la otra niña que juega a la maestra o aquella que cuida del jardín y entonces conversa con las flores. Así, por más que los varones están en las ilustraciones, las mujeres son las que aparecen actuando y tomando la palabra para conducir la acción doméstica o de cuidado de otros/as (en todos estos casos). ${ }^{12}$

En consecuencia, el Mundo feliz de Sarah Kay es infantil y femenino. Es un Mundo suave, de colores pasteles, amistoso, tierno, encantador y 12 John Berger (1980) analiza cómo las mujeres fueron representadas por los artistas plásticos y, entonces, dice: los varones están, las mujeres aparecen, irrumpen en acción. A lo que agregamos, aparecen ganado muy dulce (atiborrado de golosinas).

En estas historias no hay príncipes azules ni princesas felices. En ellas habitan niñas y niños de diferentes edades (marcadas por la estatura y por el vestuario más que por las facciones). Granjeros y granjeras sencillos/as, simples, puros/as y afables. Los espacios donde aparecen retratados/as no se distinguen en muchos casos, pero cuando se los puede visualizar son puntuales y reiterados: en interiores (dependencias de la casa de familia: cocina, sala, baño, dormitorio, etc.) o en exteriores donde se recrea una idea de naturaleza entendida en términos rurales (el río, el jardín y el sendero ligados a la granja), aunque ello no 
obsta la presencia en el mercado (frutas y verduras), la feria y el parque (carruseles, columpios). Las niñas van con sus canastos a comprar las frutas y verduras de reciente cosecha o el pescado recién traído del río. De esta forma, podemos afirmar que el Mundo feliz transcurre en ambientes domésticos y cercanos a la naturaleza: el patio de la granja, la cocina, la habitación de costura, el salón femenino, el dormitorio, etc. De manera recurrente los/as personajes posan cerca de ventanas que permiten ver un exterior no exento de rasgos entre rurales y naturales (la pequeña granja).

A su vez, los/as protagonistas son capturados/as por los trazos de la dibujante en acciones: juegan, curan, cocinan, regalan, sirven, lavan ropa, compran en el mercado ambulante (feria), pasean, cultivan, pescan, se bañan, se visten, se maquillan, comen, dan de comer, escriben, pintan, bailan, etc. En general se los encuentra en situación de juego: a la maestra, a la enfermera, a la mamá. En este Mundo hay muchos juguetes: muñecas, cunas, animales de felpa (osos, elefantes, jirafas, etc.). Por otra parte, cuando los/as personajes son adolescentes se los percibe distendidos a la vera de un arroyo, bajo la sombra de un árbol, sobre el césped, haciendo pícnic, conversando junto a un pozo de agua, escuchando música, tocando el piano, escribiendo (cartas o diarios, con una pluma, sentadas/os a un secretario).

Así grafica Sarah Kay el Mundo feliz donde la feminidad persigue el inevitable camino del amor romántico, el cuidado 


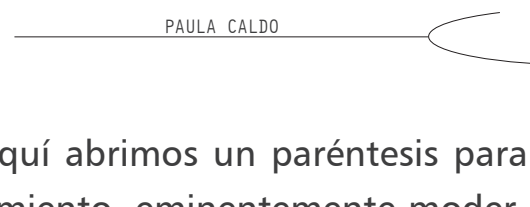

del hogar y la maternidad. Aquí abrimos un paréntesis para
introducir una línea de pensamiento, eminentemente moderna, que a nuestro entender recrea la semántica que transmiten los dibujitos de Sarah Kay. Salvando las distancias temporales, esas muchachas, simples a todas luces, recuerdan a la Julia o a la Sofía de Jean-Jacques Rousseau. Las chicas Sarah Kay son alegres, regordetas, bulliciosas, luciendo vestidos sueltos y estampados con flores y lunares, golosas (preferentemente de golosinas y dulces), sencillas pero refinadas, hacendosas y siempre situadas en ambientes que, por su especificidad o por sus fondos neutros, emparentan con la tierra, la naturaleza y lo doméstico (Caldo, 2009). Estimamos que, algo de esa representación femenina, escamotea la cita de referencia a la joven Sofía que Rousseau escogió para ser la esposa perfecta de Emilio:

Sofía es bien nacida, es de buena condición, tiene el corazón muy sensible y esta extrema sensibilidad le da a veces una actividad de imaginación difícil de moderar... Sofía no es bella, pero a su lado los hombres se olvidan de las mujeres hermosas..., ella encanta y no se acertaría a decir el porqué... a Sofía le gusta el adorno y lo sabe... pero odia los ricos atavíos, se ve siempre en el suyo la sencillez unida a la elegancia... Ignora cuáles son los colores de moda, pero sabe a maravilla cuáles son lo que le son favorables... Lo que mejor sabe hacer Sofía, y lo que 
se le ha hecho aprender con mayor cuidado, son los saberes de su sexo, incluso aquellos que no son corrientes, como cortar y coser sus vestidos... Formada para ser un día madre de familia ella también, al dirigir la casa paterna, aprende a dirigir la suya... Sofía es mucho más que limpia, es pura... Sofía era golosa. Lo era naturalmente; pero llegó a ser sobria por el hábito y ahora lo es por la virtud... (Rousseau, 1985: 454-456).

Rousseau, asumiendo que varones y mujeres poseen idéntica naturaleza puesto que pertenecen a la misma especie, inscribió la diferencia justamente en las características que asigna sobre ellos/as el sexo. Por tanto expresó que, mientras los varones actúan siempre como miembros de la especie, las mujeres lo hacen generalmente guiadas por el sexo (femenino). De este modo, ellas son agudas, sensibles, poseen una razón práctica y son intuitivas, quedando así destinadas a depender del varón. Esa razón práctica amerita para su tratamiento una educación activa a partir de la cual las muchachas puedan percibir en cada acción el sentido y la utilidad de la misma. Esto es así porque, de no hallar el sentido práctico, entran en una cadencia de aburrimiento que las conduce a la torpeza, al vicio, al desgano, a la coquetería y a la vanidad. Más que leer libremente, la mujer debe estar ocupada en lecturas acorde a su entendimiento y a las labores de su sexo. Aquellas labores que, siglos después, veremos ilustradas por Sarah Kay: lavar, planchar, vestir, cuidar al otro, 


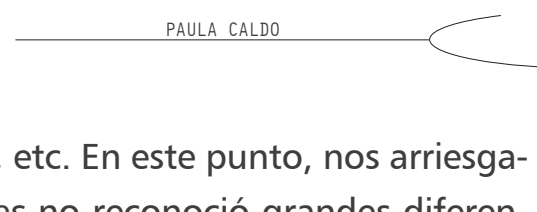

cultivar el jardín, servir, cocinar, etc. En este punto, nos arriesgamos a afirmar que Jean-Jacques no reconoció grandes diferencias entre el ser mujer y el ser niño/a. Ambas condiciones estuvieron marcadas por: la heteronomía, la dependencia, la necesidad de cuidado, la carencia, la demanda de tutela permanente. Capitalizando esta similitud y en función de respetar la educación natural que contempla al niño en sus modos particulares de ser, sentir y actuar, es que el ginebrino fija como educadora de esa primera infancia a la madre (Rousseau, 2007).

Ahora bien, el Mundo Feliz de Sarah Kay, además de exhibirse en esos libros de breves historias, lo hizo por medio de un álbum de estampas de colección reeditado varias veces y en diferentes épocas. ${ }^{13}$

El álbum empezó a circular en 1980 bajo el título Figuritas Te quiero de Sarah Kay. En la portada se veía una pareja de

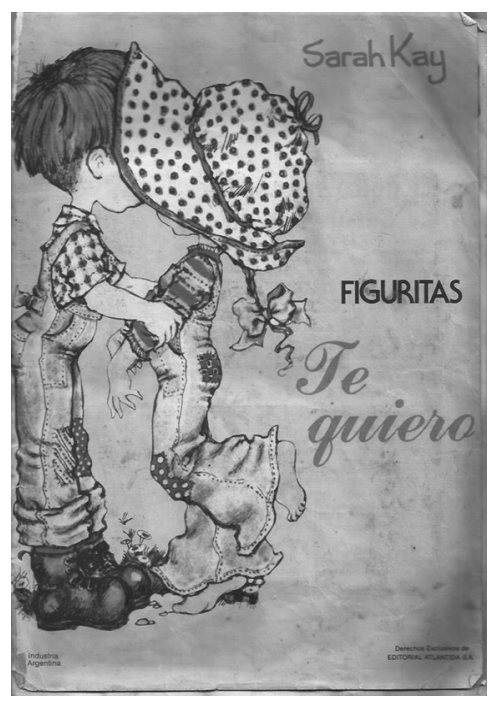
${ }^{13}$ Las ediciones del álbum de 1980 provenían de Atlántida pero también encontramos ediciones de 1991 e incluso una de 2011 a cargo de la editorial Sticker Design (Buenos Aires). adolescentes de perfil dándose un beso que quedaba oculto bajo el ala del sombrero de la muchacha. El álbum y los sobres de figuritas se compraban en los kioscos de diarios y de golosinas. Eran 140, divididas en secciones distinguidas por los títulos y epígrafes que detallamos a continuación: 
Tú eres mi mejor amigo: buenos amigos hay pocos, porque es difícil ser un buen amigo. Debes saber hablar o callar en el momento oportuno, ser decidido y paciente, dar y agradecer, amar y renunciar. Pero en todo momento hace falta ser fiel a la amistad (Kay, 1981: 1).

En mi casa: En mi casa todo es muy lindo, la cocina, el jardín, el patio... Solamente que no se termina nunca de lavar, ordenar, lustrar... (5).

Mis pequeños amigos: El gato sobre el techo, los pajaritos en el bosque, los pescaditos en el río, los perros, las ratas de campo, las gallinas y en el medio estás tú... (9).

Pienso en ti: Te extraño mucho..., pienso en ti y siento el deseo de volver a verte y quedarme a tu lado. Hasta que no podamos hacerlo continuaré pensando en ti... (12).

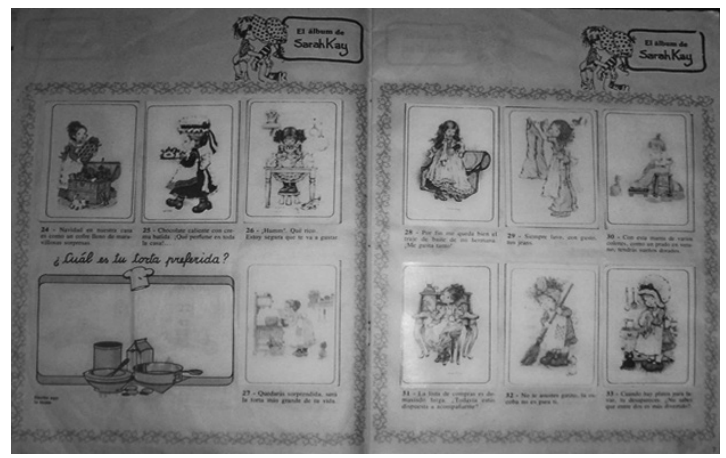

Ven a jugar conmigo: Dos más dos son cuatro, tú juegas conmigo, yo juego contigo, así que nosotros dos ya somos cuatro (17).

En el jardín: Las flores son como nobles pensamientos. 


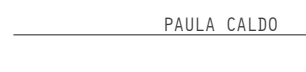

Déjalos crecer. Cuídalos y consérvalos. Reparte flores como repartes los agradables pensamientos. Volverán a ti aún mejores (22).

Muchas felicidades en tu cumpleaños: Un cumpleaños se debe celebrar siempre y en cualquier lugar. No pienses que te haces mayor iCelebra tu nacimiento! (25).

Te quiero mucho: Cada persona que ama, es igual a dos: ella y el ser amado. Quien ama busca sentir con el corazón del otro y pensar con la mente del otro. Cuando el ser querido siente y piensa del mismo modo de quien lo ama, los dos seres son uno solo... (29).

Los tópicos centrales del álbum son la amistad, el amor y el cuidado del otro. Este último da carnadura empírica a los dos primeros, puesto que muestra a los Sarah Kay en acción: practicando la amistad, cuidando de las mascotas, cultivando el jardín, halagando a los amigos, curando, celebrando y colaborando, pero también resolviendo los quehaceres domésticos o ensayando actividades artísticas (pintura, música, dibujo, etc.).

El total de la propuesta termina estableciendo como destinatarias ideales a las mujeres. Es interesante detenerse en la sección En mi casa, porque en ella se muestran 19 ilustraciones exclusivamente de niñas. En la serie pueden discriminarse tanto las actividades como los lugares propios de mujeres. Entre 
las primeras se cuentan: cocinar, lavar, tejer, coser, bordar, pintar, servir, arreglar la ropa, maquillarse, vestirse, bañarse, escribir cartas, cantar; entre los segundos se contemplan: la cocina, el baño, el dormitorio, el salón de costura, el comedor, el parque. Es importante advertir que, en el pie de imagen, las muchachas reniegan de sus quehaceres pero igualmente los ejecutan en función del halago que causa hacerlo por los otros. ${ }^{14}$

${ }^{14}$ Por ejemplo, la figura 20 dice: "Quitar el polvo es aburrido ¿Pero qué no se haría por los invitados?”. La 33 expresa: "Cuando hay platos para lavar, tú desapareces ¿No sabes que entre dos es más divertido?". La 26 propone: "iHmmmm! Qué rico, estoy segura que te va a gustar", y la 25, poniendo en palabras el pensamiento de una muchacha del personal doméstico mientras realizaba sus tareas en el servicio: "Chocolate caliente con crema batida iQué perfume en toda la casa!” (Kay, 1981:3, 4 y 5).
Donde sí aparecen los varones es en aquellas viñetas que aluden a la amistad, a los juegos y al cuidado del otro. Pero las voces que describen la imagen son siempre de niñas. Por lo tanto, el Mundo feliz de Sarah Kay es infantil y femenino.

\section{LAS NIÑAS SARAH KAY \\ O LOS EFECTOS \\ DE LA PERFORMATIVIDAD \\ (A MODO DE CIERRE)}

En la década de los 80, la ilustradora Sarah Kay comenzó a ser conocida en todo el mundo y se convirtió en una artista célebre. Su universo impregnado de dulzura y de romanticismo sigue haciendo soñar a millones de niñas. Los personajes que creó transmiten la dicha y la ternura de los temas propios de la infancia: la amistad, la naturaleza, los animales, los juguetes... 


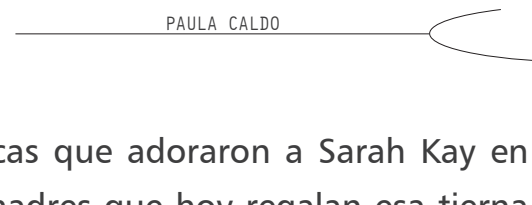
su infancia son las madres que hoy regalan esa tierna herencia a sus hijas, en un mundo que se muestra cada vez más alejado de los valores simples y esenciales... (Kay, 2006: 1).

El epígrafe, escrito en el año 2006, invita a las madres a activar la cadena de transmisión y hacer a sus hijas herederas del legado Sarah Kay. Entre mujeres, las líneas de transmisión suelen desarrollarse en lugares domésticos, privados, en la charla diaria, en el susurro, en el gesto que se reitera y hace feminidad. Justamente, cada una de las representaciones de Sarah Kay recupera notas de esa domesticidad sencilla y de apariencia pura que imprime modos y conductas en las mujeres. ${ }^{15}$

A la vez, el legado trasmitido por las ilustraciones se define como representativo de los valores fundamentales de la infancia: amistad, naturaleza, animales y juguetes. Sin embargo, lo que el epígrafe

${ }^{15}$ Para abordar el concepto de transmisión en general Jacques Hassoun (1996). Para el caso de la transmisión entre mujeres hemos consultado: Michel de Certeau, Luce Giard y Pierre Mayol (De Certeau et al., 2006) y Sharon Marcus (2007). no dice es que el mundo inocente, tierno y fresco de Sarah Kay comprende otra herencia: los valores y principios de la mujer doméstica, funcionales a la cultura patriarcal, y naturalizados y transmitidos en la educación de las niñas. Donde los criterios de belleza, delicadeza, ternura y sensibilidad se cuelan a los efectos de modelar cuerpos y conductas. 
Henry Giroux (1996), en sus Placeres inquietantes, analiza una serie de producciones culturales de apariencia ingenua que, bajo la capa, tramitan rigurosos sentidos tendientes a la domesticación y al disciplinamiento. En ellos opera lo que el citado autor llama irónicamente una pedagogía de la inocencia. Así, envueltos en un discurso ameno, sensible e ingenuo, se activan principios que poseen claras direccionalidades e intenciones. Ternura, encanto y delicadeza son las expresiones que provocan las representaciones gráficas de Sarah Kay, representaciones asociadas a la infancia y a lo femenino. Casi en un juego de espejos, las imágenes, como textos sin palabras, proponen impactar en los sentidos de las observadoras, indicando modos de ser y de aparecer en el mundo. Todo lo que esos personajes muestran posee un sentido que suma a las intenciones de la puesta en escena: los colores, las formas, las prácticas, los contextos vienen a desplegar un modo de ser, de aparecer y de estar en el mundo en general y en el mundo feliz de la infancia y la feminidad en particular.

Como toda imagen, las producidas por los trazos de la dibujante australiana, cual "vectores visibles de ideas" (Burucúa, 2001: 39), tenían el cometido de encantar a mujeres de todas las edades (niñas, adolescentes o adultas). Para todas ellas, la serie desplegaba los detalles y sentidos de un mundo feliz: en este caso el del hogar doméstico, morada de la familia nuclear. La representación pictórica permite la posibilidad de ser transitada por un público amplio para cuya interpretación lo 


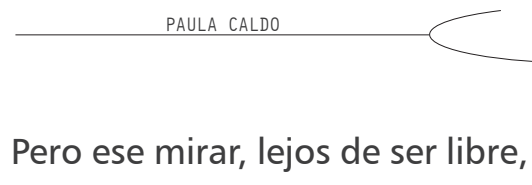

único que debe hacer es mirar. Pero ese mirar, lejos de ser libre, se encuentra atrapado en una red polisémica, autogenerada por la imagen, que permite la convergencia de niñas y adultas gozando de los mismos colores, trazos, líneas y formatos. Sin embargo, ese aire de apertura no deja de estar orientado en cuanto a la creación de sentido. Esto es: más allá de las edades, quien mira y disfruta de la propuesta de Sarah Kay termina, en última instancia, disfrutando de los elementos centrales del modelo de sociedad patriarcal. De tal suerte, en portalápices, carpetas, diarios, papeles de cartas, hojas, cuadernos y lápices, pero también en los libros de lectura placentera y finalmente en el intercambio de figuritas, los productos de Sarah Kay aparecen ornamentando las prácticas de la feminidad. Y esa ornamentación (estetización), lejos de ser ingenua, es política e intencional. Colores, formas y texturas a diario van impactando visualmente y contribuyen a generar lo que la teórica norteamericana Judith Butler llamó performatividad del género. Así, en la reiteración de los discursos plagados de normas y de prescripciones, van haciéndose los cuerpos sexuados en dirección a una ubicación siempre inestable (y muchas veces resistida) en el marco del patrón heterosexual (Butler, 2005; 2001; 1998). Esta lectura, que sitúa el análisis en relación con el orden del discurso, resulta susceptible de permearse dentro del campo pedagógico con el propósito de historiar aquellos textos orales, escritos o, como en nuestro caso, visuales que, en el largo plazo, se reiteran con fuerzas prescriptivas. 
La misma Judith Butler afirmó: "el género no es un sustantivo ni una serie de atributos vagos, ya que su efecto se produce performativamente. El género es un hacer, aunque no un hacer por parte de un sujeto que se puede considerar preexistente a la acción" (2001:58). Posteriormente agregó: "Actos, gestos y deseos producen el efecto de un mundo interno o sustancia, pero lo hacen en la superficie del cuerpo, mediante el juego de ausencias significantes que sugieren, pero no revelan el principio organizador de la identidad como causa. Tales actos realizados son performativos en el sentido de que la esencia que expresan son inventos fabricados y mantenidos mediante signos corporales y medios discursivos" (2001:67).

La serie Sarah Kay estaba compuesta por unas 140 ilustraciones que se repetían en diferentes productos necesarios para resolver la mayor parte de las actividades, tanto escolares como recreativas, de las niñas. Esa actualización constante de los mismos colores, formas y estilos oficia de escenografía del ritual que activa la fuerza performativa timoneada por las normas del patriarcado. Las niñas Sarah Kay, además de suaves, delicadas, encantadoras, graciosas y sumamente sensibles, resultarían esposas, madres y amas de casa hacendosas. Por tanto, se apuntó a formar a una mujer que, sin descuidar su arreglo y su sensibilidad, dedicaría su vida al cuidado de la naturaleza y de todos los seres vivos (animales y plantas), pero fundamentalmente de su familia y amigos/as. 


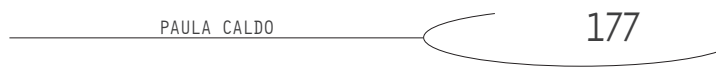

Finalmente, hemos revisado la pedagogía de la inocencia que movió los hilos internos de la propuesta de Sarah Kay. Una propuesta que acompañó a la infancia de muchas mujeres argentinas en el cruce de las décadas de 1970 y 1980. La cultura habilitó la circulación de estos dibujos que acompañaron a las niñas en sus juegos, en la escuela, en sus fiestas, en el estudio y/o lectura solitaria, etc. Esos dibujitos, lejos de ser ingenuos, dieron a ver un tipo de mujer. Por tanto, el prendamiento visual que podían generar en las consumidoras, de algún modo, impactaría en la feminidad. ${ }^{16}$ Así, las pequeñas quedarían atrapadas entre los muros de un Mundo Feliz, suave, delicado y sensible pero que, bajo la capa, llevaba dos facturas oscuras: los tiempos de la dictadura militar (un mundo para nada feliz) y los principios del patriarcado. Quizás al consumir estas imágenes las pequeñas no soñaron ${ }^{16}$ Tomamos la noción de prendamiento de Katya
Mandoki. En sus palabras: "en el acto de prenda-
miento, el sujeto se acopla a las formas de su objeto a
través de los diversos registros de experiencia (visual,
acústico, corporal o verbal) y se adhiere a la reticula-
ción semiótica que va generando a partir del objeto".
Quien queda prendado es un sujeto activo que, a par-
tir de una seguidilla de encantamientos cotidianos, va
modelando formas de ser, de actuar y de aparecer en
el mundo. Quedar prendado es hacer y ser junto con
los objetos del encantamiento (Mandoki, 2006:89). con matrimonios felices y príncipes azules, pero tal vez sus cuerpos y sus movimientos tendieron a la suavidad, la delicadeza, la simpleza y la armonía transmitida por aquellos trazos. Para cerrar con una metáfora, la elección de las ilustraciones Sarah Kay fue uno de los guantes de seda que cubrieron las manos de hierro con las cuales la pedagogía de la cultura impresa dictatorial argentina intentó domesticar a las niñas. 


\section{BIBLIOGRAFÍA}

BERGER, John (1980). Modos de ver. Barcelona: Editorial Gustavo Gili.

BONTEMPO, Paula (2012). Editorial Atlántida: un continente de publicaciones 1918-1936. Buenos Aires: Universidad de San Andrés.

BURUCÚA, José Emilio (2001). Corderos y elefantes. La sacralidad y la risa en la modernidad clásica (siglos XV a XVII). Buenos Aires: Miño y Dávila Editores. BUTLER, Judith (2005). Cuerpos que importan. Sobre los límites materiales y discursivos del sexo. Buenos Aires: Paidós.

- (2001). El género en disputa. El feminismo y la subversión de la identidad. Buenos Aires: Paidós.

- (1998). Deshacer el género. Buenos Aires: Paidós.

CALDO, Paula (2009). "Julia y Sofía. Luz y contraluz del ideal femenino de Jean-Jacques Rousseau", en Paula Caldo, Mujeres cocineras. Hacia una historia sociocultural de la cocina. Argentina a fines del siglo XIX y primera mitad del XX, pp. 27-45. Rosario: Prohistoria.

COSSE, Isabella (2014). Mafalda: Historia social y política. Buenos Aires: Fondo de Cultura Económica.

- (2009). "Los nuevos prototipos femeninos en los años 60 y 70: de la mujer doméstica a la joven liberada", en Andrea Andújar et al. (comp.), De minifaldas, militancias y revoluciones. Exploraciones sobre los setenta en la Argentina, pp. 171-186. Buenos Aires: Ediciones Luxemburg.

DE CERTEAU, Michel et al. (2006). La invención de lo cotidiano 2. Habitar, cocinar. México: Universidad Iberoamericana.

DE DIEGO, José Luis (2006). Editoriales y políticas editoriales en Argentina, 1880-2000. Buenos Aires: FCE. 


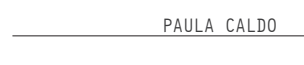

Doval, Delfina y RATTERo, Carina (2011). Autoridad y transmisión: niños y jóvenes en la mira. Buenos Aires: Noveduc.

EUJANIAN, Alejandro (1999). Historia de revistas argentinas, 1900/1950. Buenos Aires: Asociación Argentina de Editores de Revistas.

GIROUX, Henry (1996). Placeres inquietantes. Aprendiendo la cultura popular. Barcelona: Paidós.

GUITELMAN, Paula (2006). La infancia en dictadura. Modernidad y conservadurismo en el mundo de Billiken. Buenos Aires: Prometeo Libros.

HASSOUN, Jacques (1996). Los contrabandistas de la memoria. Buenos Aires:

Ediciones de la Flor.

KaUfMAnN, Carolina (2001). Dictadura y democracia. Buenos Aires: Miño y Dávila. MALOSETTI COSTA, Laura y GENÉ, Marcela (2013). Atrapados por la imagen. Arte y política en la cultura impresa argentina. Buenos Aires: Edhasa. MANDOKI, Katya (2006). Estética cotidiana y juegos de la cultura. Prosaica I. México: Siglo XXI.

MARCUS, Sharon (2007). Entre mujeres. Amistad, deseo y matrimonio en la Inglaterra victoriana. Valencia: PUV.

NARI, Marcela (2005). Políticas de maternidad y maternalismo político, Buenos Aires 1890-1940. Buenos Aires: Biblos.

RousseAU, Jean-Jacques (2007). Julia o la Nueva Eloísa. Madrid: Akal.

- (1985). Emilio o de la educación. Madrid: Edaf.

SOSENSKI CORREA, Susana (2012). “El niño consumidor. Una construcción publicitaria de la prensa mexicana en la década de 1950", en Ariadna Acevedo Rodrigo y Paula López Caballero (coords.), Ciudadanos inesperados. Espacios de formación de la ciudadanía ayer y hoy, pp. 191-223. México: El Colegio de México. 
SURIANO, Juan (2005). Nueva Historia de la Argentina. Dictadura y democracia. Buenos Aires: Editorial Sudamericana.

ULANOVSKY, Carlos (2005). Paren las rotativas. Diarios, revistas y periodistas (1920-1969). Buenos Aires: Emecé.

\section{FUENTES CITADAS}

Billiken (1979), 16 de octubre, № 3118. Buenos Aires: Editorial Atlántida.

KAY, Sarah (2007). El libro de los recuerdos. Buenos Aires: El Gato de Hojalata.

- (1983). Vamos a jugar. Buenos Aires: Editorial Atlántida.

- (1983). Un día conmigo. Buenos Aires: Editorial Atlántida.

- (1983). La granja. Buenos Aires: Editorial Atlántida.

- (1981). Álbum de figuritas Te quiero de Sarah Kay. Buenos Aires: Editorial Atlántida.

Para ti (1979). "Para tentar a cualquiera", mayo 11.

Para ti (1979). "Sarah Kay: una historia sencilla y verdadera", abril 15. 